\title{
Mechanism That Allows Manno-Oligosaccharide To Promote Cellulose Degradation By Microbes And Composting of Cow Manure With Straw
}

\section{Yuhua Zhang}

Xi'an University of Technology

Manli Duan ( $\triangle$ manli0815@163.com )

Xi'an University of Technology

Beibei Zhou

Xi'an University of Technology

Quanjiu Wang

Xi'an University of Technology

\section{Zhenshi Zhang}

Powerchina Northwest Engineering Corporation Limited

\section{Lijun Su}

Xi'an University of Technology

\section{Qingjun Bai}

Xi'an University of Technology

\section{Research Article}

Keywords: bacterial community, functional gene, lignocellulose, manno-oligosaccharide, carbon, redundancy analysis

Posted Date: August 24th, 2021

DOI: https://doi.org/10.21203/rs.3.rs-751347/v1

License: (a) (1) This work is licensed under a Creative Commons Attribution 4.0 International License. Read Full License 


\section{Abstract}

New sugar source, manno-oligosaccharide, can regulate the structure of microbes. The effects of adding manno-oligosaccharide at four different levels $(0,0.1 \%, 0.5 \%$, and $1 \% \mathrm{w} / \mathrm{w}$ compost $)$ to cow manurestraw compost on the composting process, degradation of lignocellulose, and bacterial community in this study was investigated. The results showed that adding $0.5 \%$ manno-oligosaccharide had the greatest effects on accelerating the composting process, reducing the toxicity, and improving the stability of the product. After composting for 25 days, $0.5 \%$ oligosaccharide treatment can decrease the hemicellulose, cellulose, and lignin contents to $2.25 \%, 11.25 \%$, and $7.07 \%$ respectively, compared with CK. Mannooligosaccharide affected the distribution of the bacterial community, inhibited pathogenic bacteria, and improved the abundance of functional genes. Finally, adding $0.5 \%$ manno-oligosaccharide mainly affected the degradation of lignocellulose by enhancing the $\mathrm{C} / \mathrm{N}$ value and the abundances of Streptomyces and the secretion system during composting was demonstrated by redundancy analysis.

\section{Introduction}

The manure is an inevitable by-product of the domestic animal breeding industry, the cow manure output, by-product of cow farming in the line with the report, is 13.8 billion tons in China every year (Ge et al., 2020). Considering the probable risk of cow manure bring, the aerobic composting technology is urgently needed to control the pollution efficiently, and the composting product can be regarded as a soil amendment with ecological benefits (Zhao et al., 2017; Kulcu and Yaldiz, 2004). However, cattle manure is not suitable for composting alone because of its high nitrogen content and poor air permeability, and thus a carbon conditioner must be added to improve the $\mathrm{C} / \mathrm{N}$ ratio and air permeability. Common conditioners such as wheat straw have advantages such as a high carbon content and low cost; however, wheat straw mainly comprises lignocellulose (hemicellulose, cellulose, and lignin), which has a complex structure. Lignin is an essential component of the cell wall that can resist microbial degradation, thereby requiring a long composting cycle and low degree of humification (Kluczek-Turpeinen et al., 2003). Microorganisms are mainly responsible for biodegradation of organic matter (Zhao et al., 2017). Therefore, it is important to improve the structure of the microbial community, speed up the degradation of lignocellulose and shortening the period of composting.

The degradation of compost materials is mainly driven by microorganisms (bacteria, fungi) and their metabolism (Wei et al., 2019; Gao et al., 2019). Bacteria are highly adaptable in terms of their metabolism and the lignocellulose-degrading enzymes secreted by bacteria are resistant to high temperatures (Harindintwali et al., 2020). The research found some aerobic bacteria species can degraded cellulose such as Pseudomonas, Klebsiella, and Bacillus are the important decomposers (Rainey et al., 1994; Bredholt et al., 2009; Lynd et al., 2002). Therefore, many scholars improve the bacterial community structure by inoculating bacterial strains. However, inoculating specific strains will inevitably lead to competition between the inoculated and indigenous bacteria to disrupt the benign structure of the microbial community in the compost, which is not conducive to the preservation of nutrients and improving the quality of the compost product. In addition, chemical additives can have positive effects on 
remodeling the structure of the bacterial community. For example, nanohematite can increase the abundances of bacteria to 1.24-1.58 times that in the control. Surfactants (rhamnolipid and sucrose esters) can also improve the abundances of bacteria and the capacity to metabolize carbohydrates or amino acids, thereby accelerating the bacterial degradation of cellulose and lignin (Zhang et al., 2019; Yin et al., 2019; Li et al., 2020). However, determining changes in the bacterial community is not sufficient to understand the organic matter degradation process during composting, where bacterial functional metabolism fundamentally affects the properties of compost (Duan et al., 2020). Therefore, identifying a suitable additive that can reshape the bacterial community structure and strengthen the biodegradation functions of bacteria is a feasible method for improving the aerobic composting of cow manure-straw.

Sugars are excellent sources of carbon and energy for microbes. Adding sugars or carbon sources, such as sugarcane molasses and sugar beet pulp, could improve the microbial population richness (Zhu et al., 2020b; Zhang et al., 2018). In particular, oligosaccharides are new sugar sources that are widely used in food, medicine, agriculture, and other fields. Different from common sugar sources, the oligosaccharides can significantly increase the numbers of beneficial bacteria in intestinal, inhibit the spread of harmful bacteria (Ma et al., 2020), and play the role of water retention because of their highly hydrophilic properties (Song et al., 2018). Manno-oligosaccharide (MO) is a kind of functional oligosaccharides. that are readily utilized by Bacillus subtilis and Bifidobacterium. MO and its hydrolytic derivatives can selectively regulate the structure of beneficial microorganisms, such as Bacillus subtilis and Bifidobacterium (Fu et al., 2020), and effectively inhibit pathogen growth in intestinal (Ismail et al., 2019). In addition, $\mathrm{MO}$ can improve the metabolic pathways of Clostridium butyricum, and then reduce the $\mathrm{pH}$ during the fermentation of manure (Wei et al., 2020), and produce laccases that can degrade lignin (Zang et al., 2015). However, the possible roles of MO as regulators of microbial flora and their effects on the microbial community structure and microbial functional diversity during composting have not been reported previously.

The present study investigated the effects of adding $\mathrm{MO}$ to cow manure-straw during aerobic composting on the composting process and the degradation of cellulose. The mechanism that might allow $\mathrm{MO}$ to affect the bacterial community structure and functional metabolism during composting was investigated, and the optimal amount of added MO was determined. The aim of this study was to provide a theoretical basis and technical support for agricultural waste treatment and sustainable development of the ecological environment.

\section{Materials And Methods}

\subsection{Experimental design and sample collection}

The fresh cow manure and straw in raw compost materials were collected from Shaanxi Qinbao Animal Husbandry Co. Ltd and a local farm in Yangling, China respectively. The cow manure and straw were determined after air drying and crushing, and the basic characteristics were shown in Table 1. The MO applied in the experiment was purchased from China Wanbang Industrial Co. Ltd. 
Table 1

Basic characteristics of raw materials for aerobic composting.

\begin{tabular}{|llllllll|}
\hline Materials & $\mathrm{TOC}(\mathrm{g} / \mathrm{kg})$ & $\mathrm{TN}(\mathrm{g} / \mathrm{kg})$ & $\mathrm{pH}$ & $\mathrm{MC}(\%)$ & $\mathrm{CC}(\%)$ & $\mathrm{HC}(\%)$ & $\mathrm{LC}(\%)$ \\
\hline cow manure & 292 & 16.7 & 8.41 & 7.52 & 33.9 & 26.8 & 10.5 \\
\hline straw & 414 & 6.9 & 7.61 & 5.88 & 38.0 & 28.5 & 0.4 \\
\hline
\end{tabular}

Note: TOC: Total organic carbon. TN: Total nitrogen. MC: Moisture content. CC: Cellulose content. HC: Hemicellulose content. LC: Lignin content

The composting experiment was carried out in the State Key Laboratory of Eco-hydraulics in Northwest Arid Region of China, Xi'an University of Technology from July 11, 2020 to August 6, 2020. In the composting, each treatment was mixed into cow manure $(4 \mathrm{~kg})$, straw $(2 \mathrm{~kg})$ and deionized water $(3.9 \mathrm{~L})$ to give the $\mathrm{C}: \mathrm{N}=25: 1$ and the moisture content $=65 \%$.. The experiment consists of four treatment. Without $\mathrm{MO}(\mathrm{CK})$, inoculated $0.1 \%$ (dry weight of compost) $\mathrm{MO}(01)$, inoculated $0.5 \%$ (dry weight of compost) MO (02), inoculated $1.0 \%$ (dry weight of compost) MO (03). Raw materials of 01, 02 and 03 treatment were uniformly mixed with $\mathrm{MO}$ respectively. Aerobic composting tests were carried out in four insulated foam boxes $(0.55 \mathrm{~m} \times 0.50 \mathrm{~m}$ base with $0.45 \mathrm{~m}$ high, $0.03 \mathrm{~m}$ thickness), which had two circular holes $(0.022 \times$ $0.02 \mathrm{~m}$ ) in the top, bottom, and four walls of the foam boxes to ensure ventilation and the supply of oxygen.

According to the temperature change, the whole composting experiment lasted for 25 days.

Representative samples of each treatments were taken on days $0,1,2,6,13,25$, including 6 stages: initial phase, mesophilic phase, thermophilic phase, cooling phase, primary maturation phase and secondary maturation phase. Each sample $(900 \mathrm{~g})$ is a mixture of three subsamples $(300 \mathrm{~g})$ at different depths of the compost heap and was divided in two parts. A portion of the sample was air dried to analyze its physicochemical properties, and another portion of the sample was stored at $-80^{\circ} \mathrm{C}$ for experiment $\mathrm{pH}$, $\mathrm{GI}$ (seed germination index), TOC (total organic carbon), TN (total nitrogen), WSC (water-soluble carbon) and extract DNA.

\subsection{Physicochemical properties}

The temperature of surrounding environment and composting at three points were measured at 9:00 and 18:00 daily. The moisture content of the composting sample was determined according to the weight loss after drying in a $105^{\circ} \mathrm{C}$ oven for $24 \mathrm{~h}$. The $\mathrm{pH}, \mathrm{GI}, \mathrm{TOC}, \mathrm{WSC}$ and $\mathrm{C} / \mathrm{N}$ were determined according to the previous research methods (Duan et al., 2020). The lignocellulose contents, including cellulose, hemicellulose and lignin, were determined using the method described by Van Soest. (1991) with a cellulose tester (Fibertec 2010, FOSS, Denmark). The hemicellulose, cellulose, and lignin contents were expressed as percentages of the initial total matrix.

\subsection{DNA extraction and prediction of functional gene profiles}


DNA was extracted according to the manufacturer's instructions (MP Biomedical, USA). PCR amplification of bacterial 16S rRNA genes V4 hypervariable region was performed using the universal primers 515F (GTGCCAGCMGCCGCGGTAA) and 806R (GGACTACHVGGGTWTCTAAT). Then the hypervariable region was sequenced and the raw data obtained by sequencing were spliced and filtered to obtain clean data. The high-quality sequences were clustered into Operational Taxonomic Units (OTUs) at $97 \%$ sequence identity by UPARSE software. The sequences with the highest occurrence frequency in OTUs were selected as the representative sequences of OTUs, and species annotation was made for each OTU sequence to obtain the corresponding species information and specie-based abundance distribution. Qiime software (Version 1.9.1) was used to calculate the index of Observed-

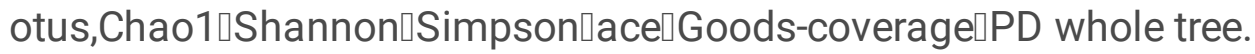

\subsection{Data analysis}

Microsoft Excel 2018 was used to conduct statistical analyses of the data. SPSS 22.0 was employed to calculate the standard errors and to test for significance differences at $P<0.05$. Sigma Plot 14.0 and TB tools were used to draw the graphics. Redundancy analysis (RDA) by Canoco 5.0.

\section{Results And Discussion}

\subsection{Physicochemical properties of compost}

Table 2 shows the changes in the physicochemical properties of the compost during different stages. The temperatures in all treatments increased to their highest levels $\left(>60^{\circ} \mathrm{C}\right)$ on day 2 . The reason for this result might be that microorganisms prioritized to use the easily degradable organic components. The thermophilic phase in 02 treatment had the highest temperature, which was consistent with Zhu (2020b) on the impact of sugarcane molasses on the composting temperature, indicating that nutrient-regulating substances could effectively increase the temperature in thermophilic phase. However, the duration of high temperature for all treatments in this study was relatively short, which could be related to the size of the compost (Meng et al., 2020). The pH increased at the beginning of the composting and then decreased. The increase in the $\mathrm{pH}$ might have related to the mineralization of nitrogen-containing organic matter. And a large amount of nitrogen was released from the compost in the form of ammonium nitrogen (Yang et al., 2019). As the composting process continued, ammonia volatilization and nitrification increased, and inorganic acids and organic acids were produced, and thus the presence of $\mathrm{H}^{+}$ made the $\mathrm{pH}$ decrease gradually before it then tended to stabilize (Zhang et al., 2017). At the end of the composting process, the $\mathrm{pH}$ value decreased most significantly in the $\mathrm{O} 2$ treatment compared with the other treatments $(P<0.05)$. 
Table 2

Changes in physicochemical properties (temperature, $\mathrm{pH}, \mathrm{C} / \mathrm{N}$ ratio (total organic carbon/total nitrogen), and seed germination index (GI)) under different treatments during composting $(n=3)$.

\begin{tabular}{|c|c|c|c|c|c|}
\hline Treatmen & & Temperature $\left({ }^{\circ} \mathrm{C}\right)$ & $\mathrm{pH}$ & $\mathrm{C} / \mathrm{N}$ & GI (\%) \\
\hline Day 0 & CK & $30.0 \pm 1.2 \mathrm{a}$ & $7.79 \pm 0.01 a$ & 24.7 & $23.3 \pm 3.1 \mathrm{a}$ \\
\hline \multirow[t]{4}{*}{ Day 1} & CK & $43.7 \pm 1.5 c$ & $8.52 \pm 0.00 c$ & 24.4 & $31.0 \pm 3.9 b c$ \\
\hline & 01 & $52.0 \pm 2.0 \mathrm{~b}$ & $8.66 \pm 0.02 a$ & 24.7 & $35.0 \pm 0.3 b$ \\
\hline & 02 & $51.5 \pm 0.9 b$ & $8.56 \pm 0.01 b$ & 24.4 & $40.0 \pm 2.2 a$ \\
\hline & 03 & $57.8 \pm 1.9 a$ & $8.32 \pm 0.02 d$ & 24.5 & $33.5 \pm 12.1 \mathrm{bc}$ \\
\hline \multirow[t]{4}{*}{ Day 2} & CK & $57.4 \pm 1.2 b$ & $8.72 \pm 0.01 a$ & 24.5 & $41.6 \pm 2.5 a b$ \\
\hline & 01 & $62.8 \pm 1.3 a$ & $8.55 \pm 0.02 b$ & 24.2 & $39.1 \pm 0.7 b$ \\
\hline & 02 & $63.2 \pm 1.2 \mathrm{a}$ & $8.41 \pm 0.01 c$ & 23.8 & $44.8 \pm 7.9 a$ \\
\hline & 03 & $62.0 \pm 1.2 \mathrm{a}$ & $8.39 \pm 0.00 c$ & 23.8 & $42.7 \pm 1.4 a b$ \\
\hline \multirow[t]{4}{*}{ Day 6} & CK & $42.7 \pm 0.6 c$ & $8.39 \pm 0.01 a$ & 23.1 & $57.3 \pm 2.6 b$ \\
\hline & 01 & $46.7 \pm 0.5 a$ & $8.18 \pm 0.00 b$ & 22.8 & $66.7 \pm 4.4 \mathrm{a}$ \\
\hline & 02 & $46.3 \pm 1.2 a$ & $7.97 \pm 0.00 c$ & 23.3 & $64.4 \pm 4.7 a b$ \\
\hline & 03 & $44.7 \pm 1.0 \mathrm{~b}$ & $7.85 \pm 0.01 d$ & 23.1 & $62.0 \pm 1.7 a b$ \\
\hline \multirow[t]{4}{*}{ Day 13} & CK & $43.5 \pm 1.3 a$ & $8.28 \pm 0.01 a$ & 21.9 & $79.4 \pm 4.1 b$ \\
\hline & 01 & $43.3 \pm 0.5 a$ & $8.00 \pm 0.01 b$ & 20.2 & $82.4 \pm 6.0 \mathrm{ab}$ \\
\hline & 02 & $42.7 \pm 0.6 a$ & $7.57 \pm 0.00 \mathrm{~d}$ & 20.1 & $84.7 \pm 6.8 a$ \\
\hline & 03 & $39.2 \pm 0.5 b$ & $7.74 \pm 0.04 c$ & 21.3 & $69.2 \pm 2.0 \mathrm{c}$ \\
\hline \multirow[t]{4}{*}{ Day 25} & CK & $34.0 \pm 0.9 a$ & $8.14 \pm 0.01 a$ & 20.8 & $93.9 \pm 21.1 c$ \\
\hline & 01 & $32.0 \pm 0.5 a b$ & $8.06 \pm 0.03 b$ & 20.0 & $91.6 \pm 19.3 c$ \\
\hline & 02 & $31.0 \pm 0.6 a b$ & $7.68 \pm 0.02 d$ & 19.5 & $109.4 \pm 34.7 \mathrm{a}$ \\
\hline & 03 & $30.5 \pm 0.5 b$ & $7.76 \pm 0.02 c$ & 21.6 & $100.8 \pm 11.2 b$ \\
\hline \multicolumn{6}{|c|}{$\begin{array}{l}\text { Note: The } \mathrm{C} / \mathrm{N} \text { values were calculated based on the average total carbon and total nitrogen contents, } \\
\text { and they did not differ significantly. The } a, b, c, d \text { means difference between groups, and the same } \\
\text { superscripts denoted not significant difference }(P>0.05) \text {, difference superscripts denoted significant } \\
\text { difference }(P<0.05) \text {. }\end{array}$} \\
\hline
\end{tabular}

The $\mathrm{Gl}$ value in the four treatment increased in general trend. The initial $\mathrm{Gl}, 23 \%$, increased to $93 \%$ in $\mathrm{CK}$, $92 \%$ in $01,109 \%$ in 02 , and $101 \%$ in 03 in the end compliance with the compost maturity standard proposed by Bernal (2009) of $\mathrm{GI}>80 \%$. The $\mathrm{Gl}$ value was relatively high with the 02 treatment, thereby indicating that adding $0.5 \% \mathrm{MO}$ had an important effect on reducing the toxicity of the compost. Thus, 
adding $\mathrm{MO}$ at a specific concentration may have effectively inhibited the growth of harmful bacteria and promoted the reproduction of beneficial bacteria to reduce the toxicity of the compost and increase the $\mathrm{GI}$ value to some extent (Ismail et al., 2019). Similar to the findings obtained in other studies, the $\mathrm{C} / \mathrm{N}$ ratio decline in trend with the composting time (Zhao et al., 2017), and the $\mathrm{C} / \mathrm{N}$ ratio decreased significantly with the 02 treatment, possibly due to the carbon loss caused by mineralization.

\subsection{Lignocellulose contents}

Plant cell walls mainly comprise cellulose, hemicellulose, and lignin. Figure 1 a shows that the hemicellulose contents stabilized in the four treatments, after the initial decreased rapidly in mesophilic phase with the composting time, as also found by Wang et al. (2017). Because hemicellulose is an active component of lignocellulose and it can be utilized as a carbon and energy source by the microorganisms in compost (Xu et al., 2019). Microorganisms require large amounts of energy to reproduce and grow during the mesophilic and thermophilic phases of composting which made hemicellulose contents decreased rapidly. The hemicellulose contents descend with the time and tend to be stable because of the consumed by microorganisms. At the end of the composting process, the hemicellulose contents were $3.12 \%$ in $\mathrm{CK}, 2.95 \%$ in $01,2.25 \%$ in 02 , and $2.65 \%$ in 03 . Figure $1 \mathrm{~b}$ shows that the changes in the cellulose contents were similar to those in the hemicellulose contents, but the hysteresis was observed clearly, possibly due to the enzymatic degradation of cellulose being inhibited by the formation of the lignin-hemicellulose complex (Xu et al., 2019). At the end of composting process, the cellulose contents were $13.99 \%$ in $\mathrm{CK}, 12.76 \%$ in $01,11.25 \%$ in 02 , and $11.83 \%$ in 03 . Thus, the final proportions of hemicellulose and cellulose was lowest in 02 , thereby indicating that inoculation with $0.5 \%$ mannooligosaccharide effectively improved the enzymatic reaction with lignocellulose to reduce the hemicellulose and cellulose contents.

Because of its special structure, lignin is not easy to be degraded by microorganisms (Kluczek-Turpeinen et al., 2003). The lignin contents decreased slowly in initial (Fig. 1c), it was due to the preferential use of simple organic matter (polysaccharides, proteins, hemicellulose, etc.) by microorganisms. After the cooling period, the microorganisms associated with lignin degradation gradually became the dominant population, and thus the lignin content decreased more rapidly in the middle and late composting periods. At the end of the composting process, the final lignin contents were $7.76 \%$ in $\mathrm{CK}, 7.50 \%$ in 01 , $7.07 \%$ in 02 , and $7.95 \%$ in 03 . The lignin content decreased significantly in 02 in the later stage of composting, thereby indicating that adding $0.5 \% \mathrm{MO}$ could effectively adjust the microbial community structure in the compost and reduce the lignin content in this stage.

Composting usually takes a long time. Cellulase can promote the biotransformation of organic matter and it has an important role in the degradation of lignocellulose and fasten compost maturation process. Previous studies have shown that the activity of cellulase depends on the abundances and structural composition of microorganisms involved in cellulose decomposition (Goyal et al., 2005). Figure 1d shows that the cellulase activity increased initially, and peaked in the cooling stage because microorganisms could store sufficient energy to release cellulase and degrade cellulose (Du et al., 2019). Compared with the other treatments, the cellulase activity of 02 treatment was significantly higher in maturation phase, 
indicating that adding $0.5 \% \mathrm{MO}$ enhanced the microbial activity in the late stage to promote the secretion of cellulose-degrading enzymes and accelerate the degradation of cellulose.

\subsection{Carbon contents}

It is noteworthy that Fig. 2a shows TOC contents first decreased and gradually stabilized because microorganisms can degrade organic matter and the carbon will be emitted as the form of $\mathrm{CO}_{2}$ and $\mathrm{CH}_{4}$ (Pisa et al., 2020). However, with the humification strengthened and mineralization weakened during composting process, the rate of carbon loss decreased, and thus the TOC contents gradually stabilized. The carbon degradation rates of $\mathrm{CK}, 01, \mathrm{O} 2$ and 03 in the thermophilic phases (day 25) were $9.7 \%, 10.8 \%$, $11.2 \%$ and $9.0 \%$, respectively. The total TOC content in each treatment on day 26 was ranked as follows: $03(255.4 \mathrm{mg} / \mathrm{g})>\mathrm{CK}(248.9 \mathrm{mg} / \mathrm{g})>01(241.5 \mathrm{mg} / \mathrm{g})>02(238 \mathrm{mg} / \mathrm{g})$. The results indicated that a small number of $\mathrm{MO}$ could effectively improve the carbon degradation of compost, and excessive $\mathrm{MO}$ had an inhibitory effect. The carbon degradation rate in 03 treatment was the lowest, which could be explained by two reasons. The first reason was related to the high content of $\mathrm{MO}$, the existence of $\mathrm{MO}$ resulted in the high TOC content. The second reason was that microorganisms preferentially use MO, which led to the organic matter in 03 treatment could not be fully degraded in the initial stage of compost.

WSC comprises active carbon components and the WSC content can reflect the maturity and stability of compost (Bai et al., 2020). As shown in Fig. 2b, the WSC contents inside composting gradually decreased due to the presence of abundant degradable substances with high water solubility in the raw materials. As the degree of humification increased, large amounts of stable substances such as humus were formed and the water solubility of the materials decreased. Therefore, the WSC contents were low in the mature compost (Zhu et al., 2020a; Duan et al., 2020). After 25 days, the WSC contents were ranked in the order: $\mathrm{CK}(\mathrm{mg} / \mathrm{g})>01(9.07 \mathrm{mg} / \mathrm{g})>03(6.37 \mathrm{mg} / \mathrm{g})>02(5.53 \mathrm{mg} / \mathrm{g})$, and all were less than the compost maturity index (WSC $<17 \mathrm{mg} / \mathrm{g}$ ) proposed by Bernai (1998), thereby indicating that the compost products were fully mature.

\subsection{Changes in the bacterial community}

According to a previous study, compared with 02,03 treatments, the values and contents of $\mathrm{pH}, \mathrm{Gl}$, hemicellulose, cellulose and WSC in 01 treatment were closer to CK treatment. So, the Illumina HiSeq PE250 platform was used to conduct high-throughput sequencing of the variable V4 region of the 16S rRNA gene for $\mathrm{CK}, \mathrm{O2}$, and 03 . The sequencing results are shown in Fig. 3. The four bacterial phyla with the highest abundances in all treatments were Proteobacteria, Firmicutes, Actinobacteria, and Bacteroidetes, which accounted for more than $80 \%$ of the total, and the similar results was obtained in previous studies of compost (Wei et al., 2018; Akyol et al., 2019). In all of the composting stages, the highest relative bacterial abundances occurred in the thermophilic phase. The dominant phylum in this stage were Firmicutes and Actinobacteria. The addition of MO significantly changed the bacterial composition during composting, where the relative abundance of Firmicutes increased most in 02 and this phylum accounted for more than $55 \%$ of the total bacteria. The similar results were obtained in a 
previous study (Zhang et al., 2016). The high simple organic matter content (hemicellulose and cellulose) in the early stage could have been utilized directly by Firmicutes to facilitate its rapid reproduction. The simple organic matter content decreased in the cooling and maturation phase, and the relative abundance of Firmicutes decreased. The dominant phylum in the maturation phase was Proteobacteria. Correlation analysis also showed that the abundance of Proteobacteria had a strong negative correlation with the lignocellulose content (Table 3), possibly because the members of Proteobacteria remained in a dormant state during the thermophilic phase before reactivating during the cooling phase (Tkachuk et al., 2014), and the lignocellulose content decreased gradually with the composting time. In addition, Actinobacteria was the main phylum involved in cellulose degradation (DeAngelis et al., 2011) and this phylum was mainly detected in the maturation phase. Actinobacteria can regulate the activities of key enzymes to degrade lignocellulose (Wei et al., 2019). The abundance of Actinobacteria had strong positive correlations with the cellulose and lignin contents, thereby indicating that Actinobacteria made an important contribution to the degradation of lignocellulose during the composting process. Figure 3a shows that the relative abundance of Actinobacteria was highest in 02 , which explains the low cellulose and lignin contents in this treatment.

Table 3

Correlations between lignocellulose contents and bacterial phyla.

\begin{tabular}{|c|c|c|c|c|}
\hline & Proteobacteria & Firmicutes & Actinobacteria & Bacteroidetes \\
\hline Cellulose & $-0.736 * \star$ & $0.859 * \star$ & $0.679 *$ & $-0.715^{\star \star}$ \\
\hline Hemicellulose & $-0.690 * \star$ & $0.883^{* *}$ & $0.830 * *$ & $-0.754 \star \star$ \\
\hline Lignin & $-0.647 *$ & 0.817 ** & $0.766^{\star \star *}$ & $-0.683 *$ \\
\hline
\end{tabular}

At the genus level, Thermobifida (Actinobacteria) was the most abundant in all treatments, followed by Thermopolyspora (Actinobacteria), Geobacillus (Firmicutes), Planifilum (Firmicutes), and Streptomyces (Actinobacteria). The dominant bacteria differed among the various periods and treatments.

Streptomyces, Romboutsia, and Planococcus were the main genera in the early stage of composting, and Thermobifida, Bacillus, Thermopolyspora, and Planifilum were highly abundant in the thermophilic phase. Previous studies have shown that members of the genus Thermobifida in Actinobacteria can degrade cellulose (Zhang et al., 2020), which might explain the rapid decline in the cellulose contents during the thermophilic phase. The abundance of Thermobifida decreased during the composting process under all treatments, but a high abundance of Thermobifida was observed in 02 during the maturation phase, and especially in the early maturation phase. Bacillus was an abundant genus in the phylum Firmicutes. According to Gannes (2013), members of Bacillus can tolerate high temperatures and degrade lignocellulose. The abundances of Luteimonas (Proteobacteria) and Chelativorans (Proteobacteria) were high in the cooling stage, and previous studies have shown that these bacteria can degrade lignocellulose and xylan (Zhang et al., 2011). Chryseolinea, Altererythrobacter, Taibaiella, and Cellvibrio were the 
dominant bacterial genera in the maturation phase. Chryseolinea is present in the soil rhizosphere and it can improve the soil structure and crop growth (Visioli et al., 2018).

\subsection{Microbial functional genes}

During composting, the transcription and expression of the corresponding functional genes were giving the microbial functions and the secreted enzyme. The classification information for the microbial community is usually insufficient to assess its impact on the composting process (Manoharan et al., 2017; Chen et al., 2020). Therefore, it is more appropriate to analyze the effects of microorganisms during the composting process by quantifying the diversity of the microbial functional genes. In this study, PICRUSt was used to investigate the microbial functional diversity and to determine the effects of MO on the microbial functions. The level 1 KEGG prediction results (Fig. 4a) identified seven functions, which "Metabolism" accounted for 49.7-51.7\% and the largest proportion of all the functional genes, the following 15.3-16.2\%, 12.6-15.6\%, 12.8-13.8\%, 2.9-4\%, 0.8-1.2\%, 0.8-0.9\% were in genetic information processing, environmental information processing, unclassified, cellular processes, human diseases, and others, respectively. The abundances of functional genes increased in all treatments with the composting time.

The relative abundances of the first 30 functional genes among the level 3 KEGG prediction results are shown in Fig. 4b. There were some differences in the efficiencies of the bacterial functions during composting. The relative abundances of pyruvate metabolism, glycolysis/gluconeogenesis, amino sugar and nucleotide sugar metabolism genes related to carbohydrate metabolism increased during the thermophilic phase, especially 02 treatment. Similarly, Wang (2018) found that the relative abundances of genes related to the biosynthesis and metabolism of sugars and ketones increased during the thermophilic stage, and the carbon transformation was positively correlated with carbohydrate degradation genes (Hartman et al., 2017). It suggested that the rich carbohydrate metabolism genes at this stage were the main reason for the rapid degradation of lignocellulose and carbon. Membrane transcription and nucleotide metabolism also accounted for a large proportion in thermophilic stage, which was related to the rapid reproduction of microorganisms. Obviously, the relative abundance of these functional genes in 02 treatment was higher. The relative abundances of genes associated with arginine and proline metabolism, glycine, serine and threonine metabolism, and valine, leucine, and isoleucine degradation enhanced gradually in the cooling and maturation phase. This was because the carbohydrate degrading enzymes secreted by bacteria decomposed the proteins, cellulose and hemicellulose in thermophilic phases (Goh et al., 2013). A previous study also found that more sequences were annotated with roles in amino acid metabolism in this stage to significantly enhance the synthesis of humus (Wu et al., 2017). Replication, transcription, and translation are the main pathways related to bacterial enzyme secretion, and the abundances of genes associated with ribosome, chromosome, and ribosome biogenesis increased with the composting time, thereby indicating that bacteria continued to produce secretions to participate in lignocellulose metabolism. In addition, some functions were processed by genes associated with "Environmental information," such as "Secretion system," which also demonstrates that the secretion of related enzymes increased with the composting time. The propanoate 
and butanoate contents are closely related to the $\mathrm{pH}$, and the increased of butanoate metabolism and propanoate metabolism mainly explained the decrease and stabilization in the $\mathrm{pH}$ during the composting process (Duan et al., 2020). Figure 4b shows that the relative abundance of tuberculosis (human diseases) in 02 treatment was lowest in all treatments, which indicated that $0.5 \%$ of $\mathrm{MO}$ had a certain inhibitory effect on pathogenic bacteria.

\subsection{Correlations between physicochemical properties, microbial community composition, functional genes, and lignocellulose contents}

The bacterial community and its functions were affected by the physicochemical properties of compost, which affecting lignocellulose content. Thus, RDA was conducted to assess the correlations between the composting environment, microbes, and changes in the lignocellulose contents. Figure 5 shows the effects of the temperature, $\mathrm{pH}, \mathrm{C} / \mathrm{N}$, microbial community, and metabolic functions on the lignocellulose, TOC, and WSC contents. RDA1 and RDA2 accounted for $98.8 \%$ and $0.2 \%$ of the variation, respectively (Fig. 5a). Among the eight factors were considered, $\mathrm{C} / \mathrm{N}$ explained $84.5 \%$ of the total variation in the lignocellulose, TOC, and WSC contents $(P=0.002)$, Streptomyces explained $5.5 \%$ of the total variation ( $P$ $=0.012)$, temperature explained $4.9 \%$ of the total variation $(P=0.008)$, Luteimonas explained $1.7 \%$ of the total variation $(P=0.094)$, $\mathrm{pH}$ explained $1.5 \%$ of the total variation $(P=0.206)$, and Chryseolinea explained $0.8 \%$ of the total variation $(P=0.202)$. Thus, the $\mathrm{C} / \mathrm{N}$ ratio had the greatest influence on the lignocellulose content because lignocellulose is rich in carbon. Carbon loss was inevitable due to the continuous degradation of lignocellulose, and thus the $\mathrm{C} / \mathrm{N}$ ratio explained much of the total variance. The temperature was also positively correlated with the lignocellulose and carbon contents because the temperature decreased gradually with the compost matured, and the lignocellulose and carbon contents decreased due to microbial degradation. Streptomyces was the dominant genus in the early stage and it could tolerate the weak alkali environment. Studies have shown that Streptomyces can utilize lignocellulose as a sole carbon source to support growth, as well as effectively degrading hemicellulose, cellulose, and lignin (Feng et al., 2021). Luteimonas and Chryseolinea were mainly detected in the maturation phase and their abundances were negatively correlated with temperature, and thus these two bacterias were not resistant to high temperature but they were involved with the degradation of organic matter in the later stage.

As shown in Fig. 5b, RDA1 and RDA2 explained $99.1 \%$ and $0.3 \%$ of the variation in the cellulose contents, respectively. Among the eight factors were considered, $\mathrm{C} / \mathrm{N}$ still explained most of the changes in the cellulose contents during composting, where it explained $83.6 \%$ of the total variation $(P=0.002)$, while the secretion system, $\mathrm{pH}$, amino sugar and nucleotide sugar metabolism, purine metabolism, and temperature explained $4.6 \%(P=0.084), 3.3 \%(P=0.116), 1.5 \%(P=0.43), 2.3 \%(P=0.188)$, and $1.6 \%(P=$ $0.166)$, respectively. All of the functional genes were mainly distributed in the maturation stage and they had no significant negative correlations with the lignocellulose and carbon contents, mainly because the degradation of lignocellulose was more rapid in the early stage and bacterial functional genes were more abundant in the maturation stage. Compared with the other treatments, the 02 treatment had a stronger 
correlation with functional genes in the maturation phase. The results showed that adding $0.5 \% \mathrm{MO}$ could effectively improve the abundance of functional genes and degrade lignocellulose. Furthermore, the $\mathrm{pH}$ was positively correlated with the lignocellulose and carbon contents, but negatively correlated with butanoate metabolism. It is well known that the $\mathrm{pH}$ is mainly affected by the organic acids produced via the degradation of complex organic matter (e.g., lignocellulose) (Duan et al., 2020). Therefore, organic acids accumulated and the $\mathrm{pH}$ decreased as the lignocellulose contents decreased. In addition, butanoate metabolism increased and butanoate was consumed in large quantities to inhibit the accumulation of organic acids.

\section{Conclusion}

The addition of $\mathrm{MO}$ increased the temperature in the thermophilic phase. Compared with the other treatments, 02 reduced the toxicity, promoted the degradation of lignocellulose and enzymatic reactions, and improved the stability of the final compost product. MO reshaped the bacterial community structure, reduced the abundances of pathogenic bacteria, and changed the abundances of functional genes. RDA also indicated that $\mathrm{C} / \mathrm{N}$, temperature, and Streptomyces were the main factors related to lignocellulose degradation. Thus, adding $0.5 \% \mathrm{MO}$ to cow manure-straw during aerobic composting could effectively regulate the composting properties, enhance the bacterial community structure and functional genes, and promote the degradation of lignocellulose.

\section{Declarations}

\section{Statement:}

1. Ethics approval and consent to participate: Not applicable.

2. Consent for publication: All authors of the above article agree to submit their contributions to the Environmental Science and Pollution Research.

3. Availability of data and materials: The datasets used and/or analysed during the current study are available from the corresponding author on reasonable request.

4. Competing interests: The authors declare that they have no competing interests.

5. Funding: All the funding from the teacher project support.

6. Authors' contributions:

Yuhua Zhang: Formal analysis; Investigation; Methodology; Writing - original draft

Manli Duan: Funding acquisition; Project administration; Supervision; Writing - review \& editing Beibei Zhou: Funding acquisition; Supervision; Writing - review \& editing 
Quanjiu Wang: Funding acquisition; Supervision

Zhenshi Zhang: Supervision

Lijun Su: Data curation; Investigation; Methodology

Qingjun Bai: Supervision

\section{Acknowledgments}

This study was funded by the National Natural Science Foundation of China (41807131, 41977007 and 41830754), China Postdoctoral Science Foundation (2019M653707), Natural Science Foundation of Shaanxi province of China (2019JQ-537), Science and Technology Program of Xi'an, China (20NYYF0027), and Research project of State Key Laboratory of Eco-hydraulics in Northwest Arid Region of China (2019KJCXTD-4 and QJNY-2019-01). We thank Dr. Duncan E. Jackson for language editing.

\section{References}

1. Akyol C, Ince O, Ince B (2019) Crop-based composting of lignocellulosic digestates: Focus on bacterial and fungal diversity. Bioresour Technol 288:121549

2. Bai L, Deng Y, Li J, Ji M, Ruan W (2020) Role of the proportion of cattle manure and biogas residue on the degradation of lignocellulose and humification during composting. Bioresour. Technol. 122941

3. Bernai MP, Paredes C, Sanchez-Monedero MA, Cegarra J (1998) Maturity and stability parameters of composts prepared with a wide range of organic wastes. Bioresour Technol 63(1):91-99

4. Bernal MP, Alburquerque JA, Moral R (2009) Composting of animal manures and chemical criteria for compost maturity assessment. A review. Bioresour Technol 100(22):5444-5453

5. Bredholt S, Sonne-Hansen J, Nielsen P, Mathrani IM, Ahring K (1999) Caldicellulosiruptor kristjanssonii sp. nov., a cellulolytic, extremely thermophilic, anaerobic bacterium. Int J Syst Bacteriol 49(3):991-996

6. Chen H, Zhang Y, Awasthi SK, Liu T, Zhang Z, Awasthi MK (2020) Effect of red kaolin on the diversity of functional genes based on Kyoto Encyclopedia of Genes and Genomes pathways during chicken manure composting. Bioresour. Technol. 123584

7. DeAngelis KM, Allgaier M, Chavarria Y, Fortney JL, Hugenholtz P, Simmons B, Hazen TC (2011) Characterization of trapped lignin-degrading microbes in tropical forest soil. PloS One 6(4):e19306

8. Du J, Zhang Y, Qu M, Yin Y, Fan K, Hu B, Ma C (2019) Effects of biochar on the microbial activity and community structure during sewage sludge composting. Bioresour Technol 272:171-179

9. Duan M, Zhang Y, Zhou B, Qin Z, Wu J, Wang Q, Yin Y (2020) Effects of Bacillus subtilis on carbon components and microbial functional metabolism during cow manure-straw composting. Bioresour Technol 303:122868 
10. Feng J, Wang B, Zhang D, Chu S, Zhi Y, Hayat K, Zhou P (2021) Streptomyces griseorubens JSD-1 promotes rice straw composting efficiency in industrial-scale fermenter: Evaluation of change in physicochemical properties and microbial community. Bioresour Technol 321:124465

11. Fu X, Wei X, Xiao M, Han Z, Mou H (2020) Properties of hydrolyzed guar gum fermented in vitro with pig fecal inocula and its favorable impacts on microbiota. CARBOHYD POLYM 237:116116

12. Gannes V, Eudoxie G, Hickey J (2013) Prokaryotic successions and diversity in composts as revealed by 454-pyrosequencing. Bioresour Technol 133:573-580

13. Gao X, Tan W, Zhao Y, Wu J, Sun Q, Qi H, Wei Z (2019) Diversity in the mechanisms of humin formation during composting with different materials. Environ Sci Technol 53(7):3653-3662

14. Ge M, Zhou H, Shen Y, Meng H, Li R, Zhou J, Wang J (2020) Effect of aeration rates on enzymatic activity and bacterial community succession during cattle manure composting. Bioresour Technol 304:122928

15. Goh K, Kahar U, Chai Y, Chong C, Chai K, Ranjani V, Illias R, Chan K, G (2013) Recent discoveries and applications of Anoxybacillus. Appl Microbiol Biotechnol 97(4):1475-1488

16. Goyal S, Dhull SK, Kapoor KK (2005) Chemical and biological changes during composting of different organic J. Bioresour Technol 96(14):1584-1591

17. Harindintwali JD, Zhou J, Yu X (2020) Lignocellulosic crop residue composting by cellulolytic nitrogen-fixing bacteria: A novel tool for environmental sustainability. Sci Total Environ 715:136912

18. Hartman W, Ye H, Horwath R, Tringe WR, S, G (2017) A genomic perspective on stoichiometric regulation of soil carbon cycling. ISME J 11:2652

19. Ismail S, Hassan A, Emran AA, M. A (2019) Economic production of thermo-active endo $\beta$ mannanase for the removal of food stain and production of antioxidant manno-oligosaccharides. Biocatal Agric Biotechnol 22:101387

20. Kluczek-Turpeinen B, Tuomela M, Hatakka A, Hofrichter M (2003) Lignin degradation in a compost environment by the deuteromycete Paecilomyces inflate. Appl Microbiol Biotechnol 61(4):374-379

21. Kulcu R, Yaldiz O (2004) Determination of aeration rate and kinetics of composting some agricultural wastes. Bioresour Technol 93:49-57

22. Li G, Zhu Q, Jiang Z, Li M, Ma C, Li X, Li Q (2020) Roles of non-ionic surfactant sucrose ester on the conversion of organic matters and bacterial community structure during composting. Bioresour. Technol. 123279

23. Lynd R, Weimer J, Van Zyl H, Pretorius S (2002) Microbial cellulose utilization: fundamentals and biotechnology. Microbiol Mol Biol Rev 66(3):506-577

24. Ma Y, Peng X, Yang J, Giovanni V, Wang C (2020) Impacts of functional oligosaccharide on intestinal immune modulation in immunosuppressive mice. Saudi J Biol Sci 27(1):233-241

25. Manoharan L, Kushwaha SK, Ahrén D, Hedlund K (2017) Agricultural land use determines functional genetic diversity of soil microbial communities. Soil Biol Biochem 115:423-432 
26. Meng L, Li W, Zhang X, Zhao Y, Chen L, Zhang S (2020) Influence of spent mushroom substrate and molasses amendment on nitrogen loss and humification in sewage sludge composting. Heliyon 6:e04988

27. Pisa C, Wuta M, Muchaonyerwa P (2020) Effects of incorporation of vermiculite on carbon and nitrogen retention and concentration of other nutrients during composting of cattle manure. Bioresour Technol Rep 9:100383

28. Rainey A, Donnison M, Janssen H, Saul D, Rodrigo A, Bergquist L, Morgan W (1994) Description of Caldicellulosiruptor saccharolyticus gen. nov., sp. nov: an obligately anaerobic, extremely thermophilic, cellulolytic bacterium. FEMS Microbiol Lett 120(3):263-266

29. Song Q, Li T, Xue W, Li N, Chen L, Dai S, Zhu Z (2018) Preparation, structure analysis and ACE inhibitory activity of konjac oligosaccharide. Ind Crop Prod 124:812-821

30. Tkachuk VL, Krause DO, Knox NC, Hamm AC, Zvomuya F, Ominski KH, McAllister TA (2014) Targeted 16S RNA high-throughput sequencing to characterize microbial communities during composting of livestock mortalities. J Appl Microbial 116(5):1181-1194

31. Van Soest PV, Robertson JB, Lewis BA (1991) Methods for dietary fiber, neutral detergent fiber, and nonstarch polysaccharides in relation to animal nutrition. J Dairy Sci 74(10):3583-3597

32. Visioli G, Sanangelantoni AM, Vamerali T, Cortivo D, Blandino C, M (2018) 16S rDNA profiling to reveal the influence of seed-applied biostimulants on the rhizosphere of young maize plants. Molecules 23(6):1461

33. Wang K, Mao H, Wang Z, Tian Y (2018) Succession of organics metabolic function of bacterial community in swine manure composting. J Hazard Mater 360:471-480

34. Wang Q, Awasthi MK, Zhao J, Ren X, Li R, Wang Z, Zhang Z (2017) Improvement of pig manure compost lignocellulose degradation, organic matter humification and compost quality with medical stone. Bioresour Technol 243:771-777

35. Wei H, Wang L, Hassan M, Xie B (2018) Succession of the functional microbial communities and the metabolic functions in maize straw composting process. Bioresour Technol 256:333-341

36. Wei X, Fu X, Xiao M, Liu Z, Mou H (2020) Dietary galactosyl and mannosyl carbohydrates: in-vitro assessment of prebiotic effects. FOOD CHEM 329:127179

37. Wei Y, Wu D, Wei D, Zhao Y, Wu J, Xie X, Wei Z (2019) Improved lignocellulose-degrading performance during straw composting from diverse sources with actinomycetes inoculation by regulating the key enzyme activities. Bioresour Technol 271:66-74

38. Wu J, Zhao Y, Qi H, Zhao X, Yang T, Du Y, Wei Z (2017) Identifying the key factors that affect the formation of humic substance during different materials composting. Bioresour Technol 244:11931196

39. Xu J, Jiang Z, Li M, Li Q (2019) A compost-derived thermophilic microbial consortium enhances the humification process and alters the microbial diversity during composting. $\mathrm{J}$ Environ Manage 243:240-249 
40. Yang C, Han Z, Ruan Y, Chai J, Jiang W (2019) Composting swine carcasses with nitrogen transformation microbial strains: Succession of microbial community and nitrogen functional genes. Sci Total Environ 688:555-566

41. Yin Y, Yang C, Gu J, Wang X, Zheng W, Wang R, Chen R (2019) Roles of nxrA-like oxidizers and nirSlike reducers in nitrite conversion during swine manure composting. Bioresour Technol 297:122426

42. Zang H, Xie S, Wu H, Wang W, Shao X, Wu L, Rajer F, Gao U, X (2015) A novel thermostable GH5_7 $\beta$ mannanase from Bacillus pumilus GBSW19 and its application in manno-oligosaccharides (MOS) production. Enzym Microb Technol 78:1-9

43. Zhang D, Luo W, Yuan J, Li G, Luo Y (2017) Effects of woody peat and superphosphate on compost maturity and gaseous emissions during pig manure composting. Waste Manage 68:56-63

44. Zhang J, Siika-aho M, Puranen T, Tang M, Tenkanen M, Viikari L (2011) Thermostable recombinant xylanases from Nonomuraea flexuosa and Thermoascus aurantiacus show distinct properties in the hydrolysis of xylans and pretreated wheat straw. Biotechnol Biofuels 4(1):12

45. Zhang L, Dong H, Zhu Y, Zhang J, Zeng G, Yuan Y, Fang W (2019) Evolutions of different microbial populations and the relationships with matrix properties during agricultural waste composting with amendment of iron (hydr) oxide nanoparticles. Bioresour Technol 289:121697

46. Zhang L, Sun X (2018) Influence of sugar beet pulp and paper waste as bulking agents on physical, chemical, and microbial properties during green waste composting. Bioresour Technol 267:182-191

47. Zhang $L$, Zhang $H$, Wang $Z$, Chen $G$, Wang $L$ (2016) Dynamic changes of the dominant functioning microbial community in the compost of a $90-\mathrm{m} 3$ aerobic solid state fermentor revealed by integrated meta-omics. Bioresour Technol 203:1-10

48. Zhang W, Yu C, Wang X, Hai L (2020) Increased abundance of nitrogen transforming bacteria by higher $\mathrm{C} / \mathrm{N}$ ratio reduces the total losses of $\mathrm{N}$ and $\mathrm{C}$ in chicken manure and corn stover mix composting. Bioresour Technol 297:122410

49. Zhao Y, Zhao Y, Zhang Z, Wei Y, Wang H, Lu Q, Wei Z (2017) Effect of thermo-tolerant actinomycetes inoculation on cellulose degradation and the formation of humic substances during composting. Waste Manage 68:64-73

50. Zhu L, Wei Z, Yang T, Zhao X, Dang Q, Chen X, Zhao Y (2020a) Core microorganisms promote the transformation of DOM fractions with different molecular weights to improve the stability during composting. Bioresour Technol 299:122575

51. Zhu Q, Li G, Jiang Z, Li M, Ma C, Li X (2020b) Investigating the variation of dissolved organic matters and the evolution of autotrophic microbial community in composting with organic and inorganic carbon sources. Bioresour Technol 304:123013

\section{Figures}




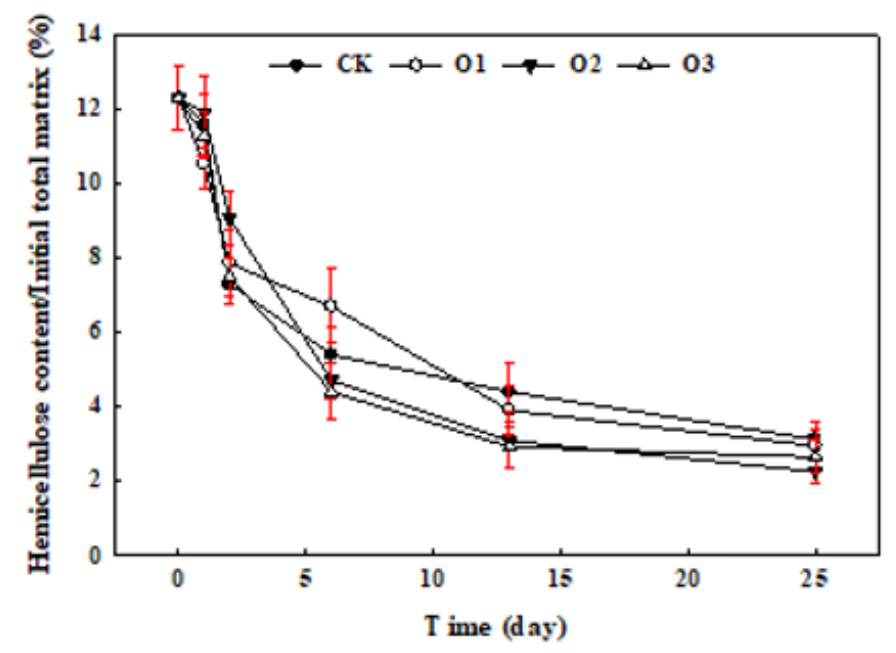

(a)

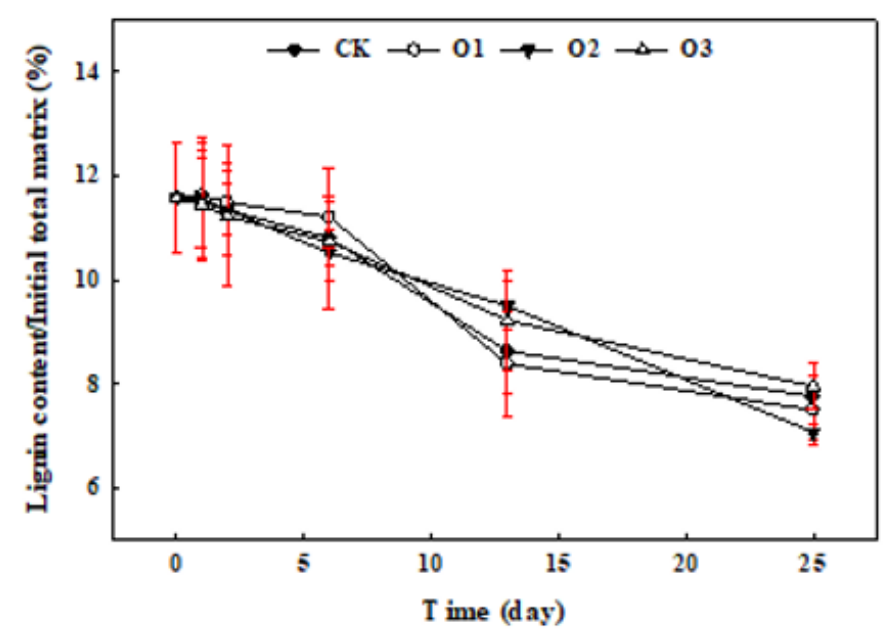

(c)

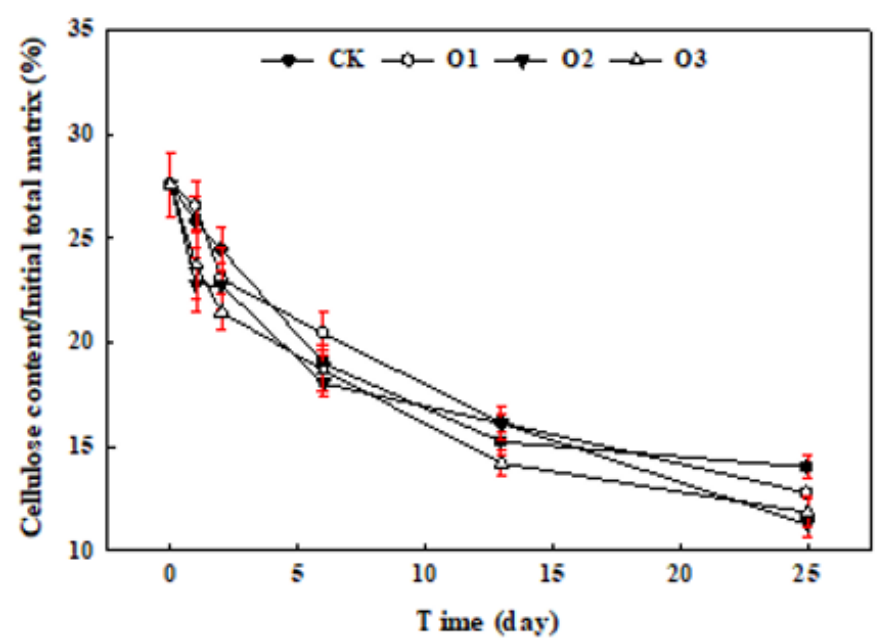

(b)

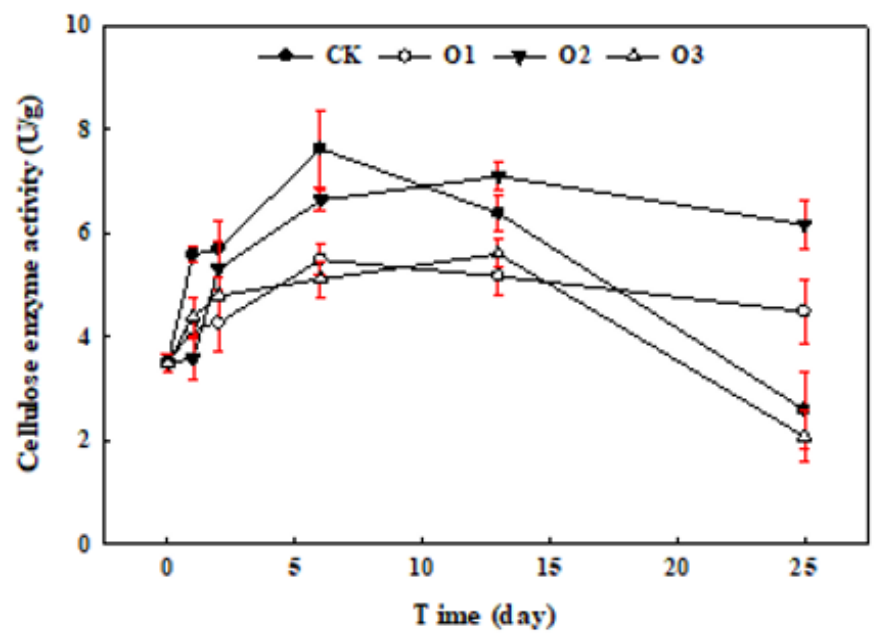

(d)

\section{Figure 1}

Changes in hemicellulose, cellulose, and lignin contents, and cellulose enzyme activity during composting: (a) hemicellulose; (b) cellulose; (c) lignin; and (d) cellulose enzyme activity. The hemicellulose, cellulose, and lignin content represent the percentages relative to the initial values in the total compost matrix $(n=3)$. 


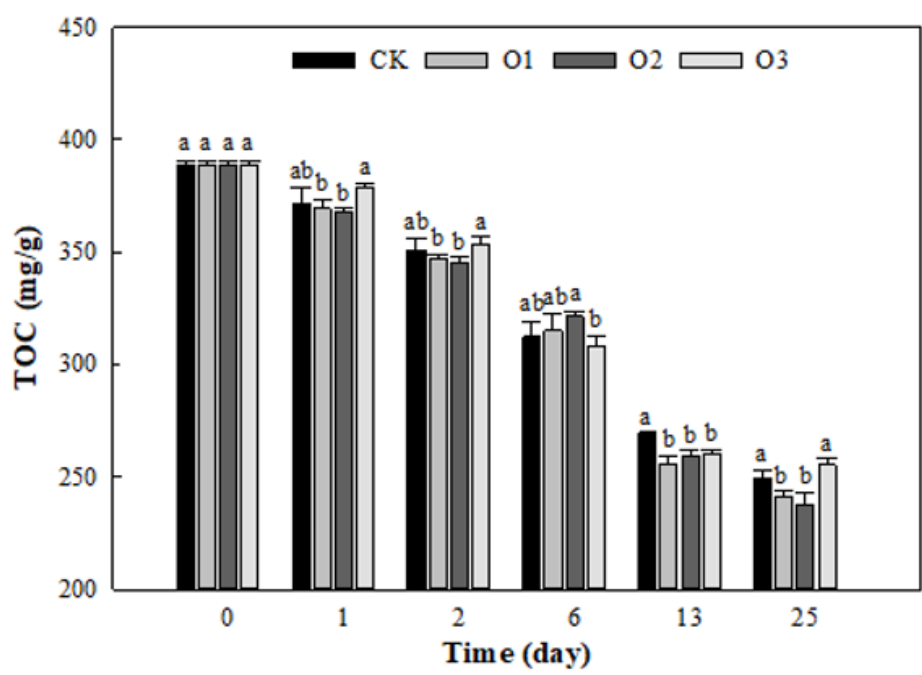

(a)

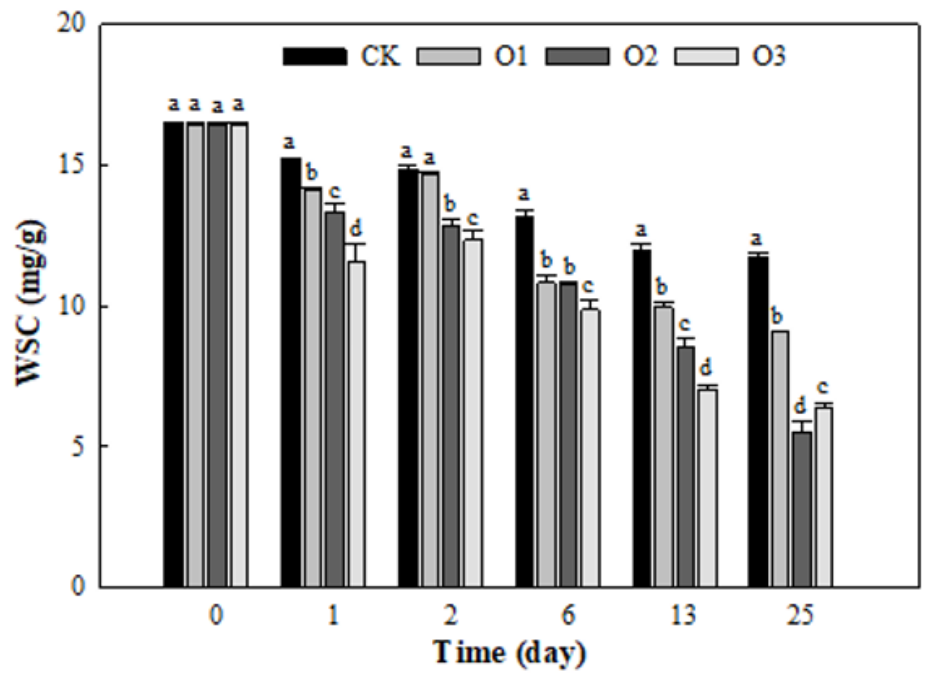

(b)

\section{Figure 2}

Changes in total organic carbon (TOC) and water-soluble carbon (WSC) contents during composting: (a) TOC, and (b) WSC. The bars represent standard deviations $(n=3)$. Note: The $a, b, c, d$ means difference between groups, and the same superscripts denoted not significant difference $(P>0.05)$, difference superscripts denoted significant difference $(P<0.05)$.

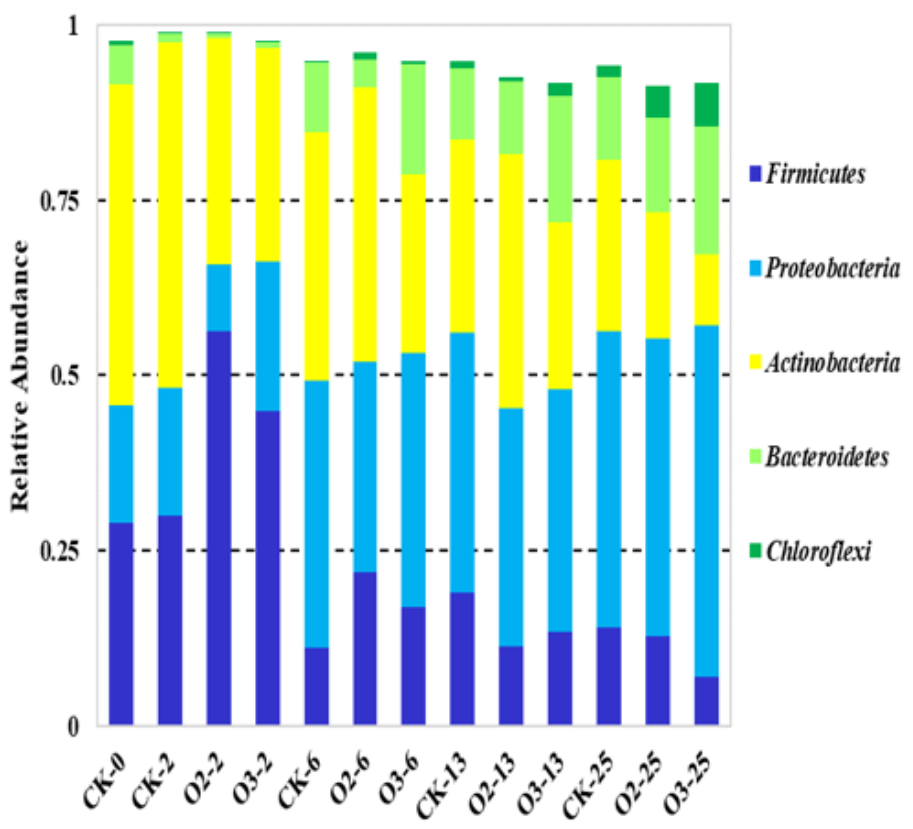

Sample Name

(a)

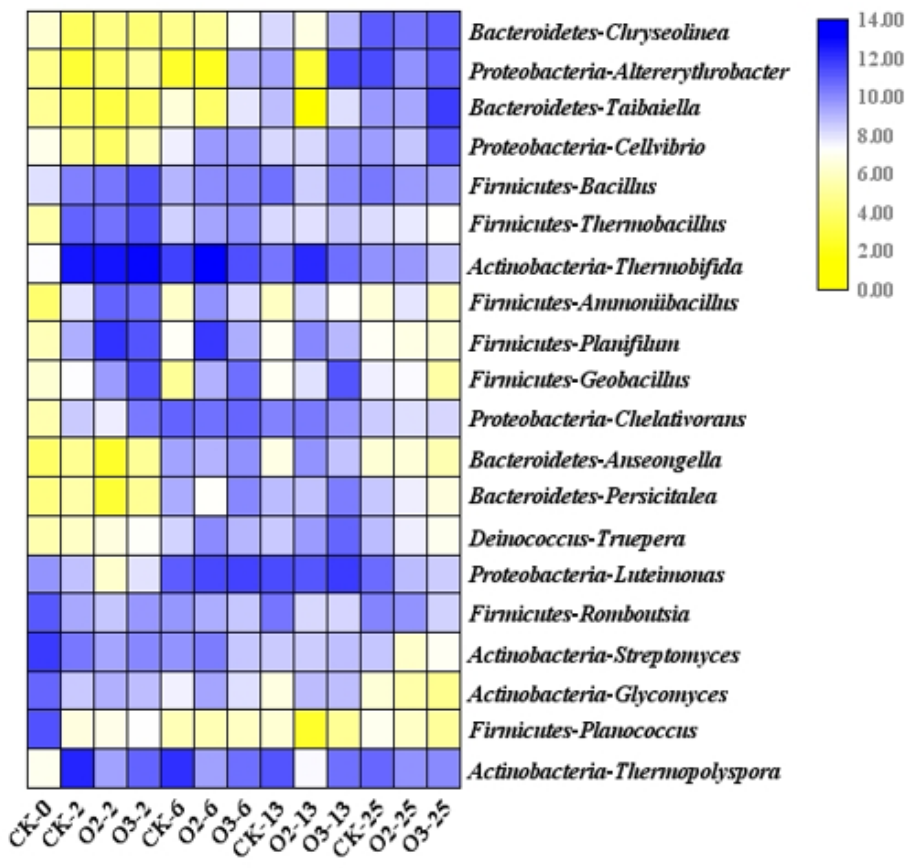

(b)

\section{Figure 3}

Changes in relative abundances of bacteria during composting: (a) relative abundances of bacterial phyla and (b) relative abundances of bacterial genera. 


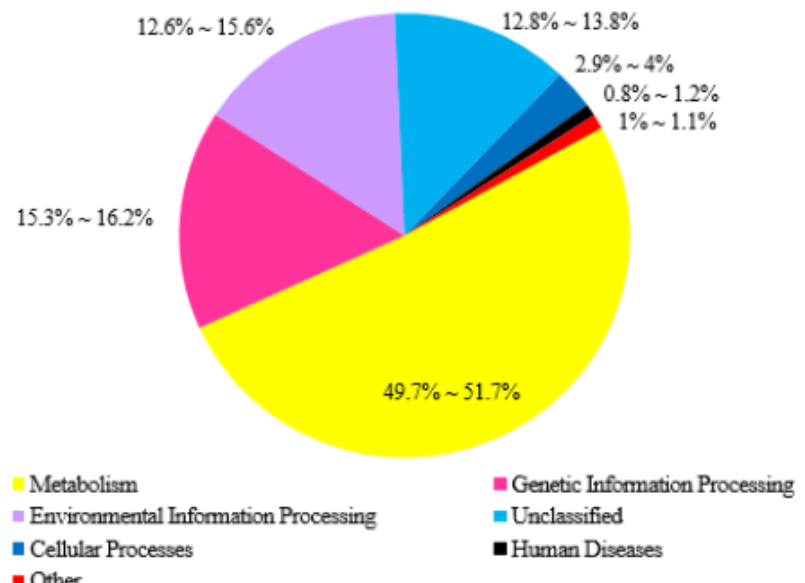

(a)

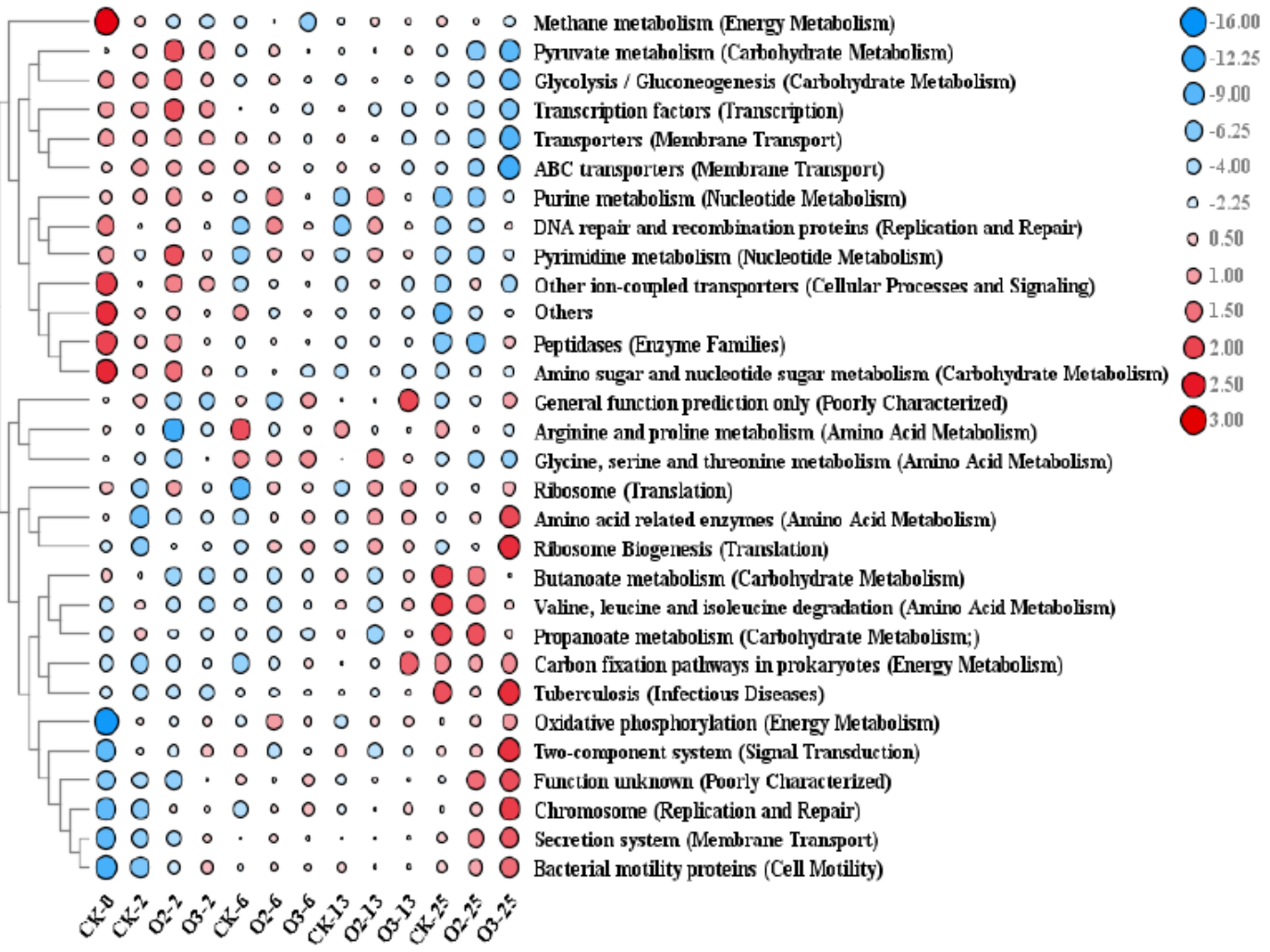

\section{Figure 4}

Changes in relative abundances of microbial functional genes during composting: (a) biochemical functional gene pathways, and (b) level 3 KEGG function predictions for the 30 main functional genes. 


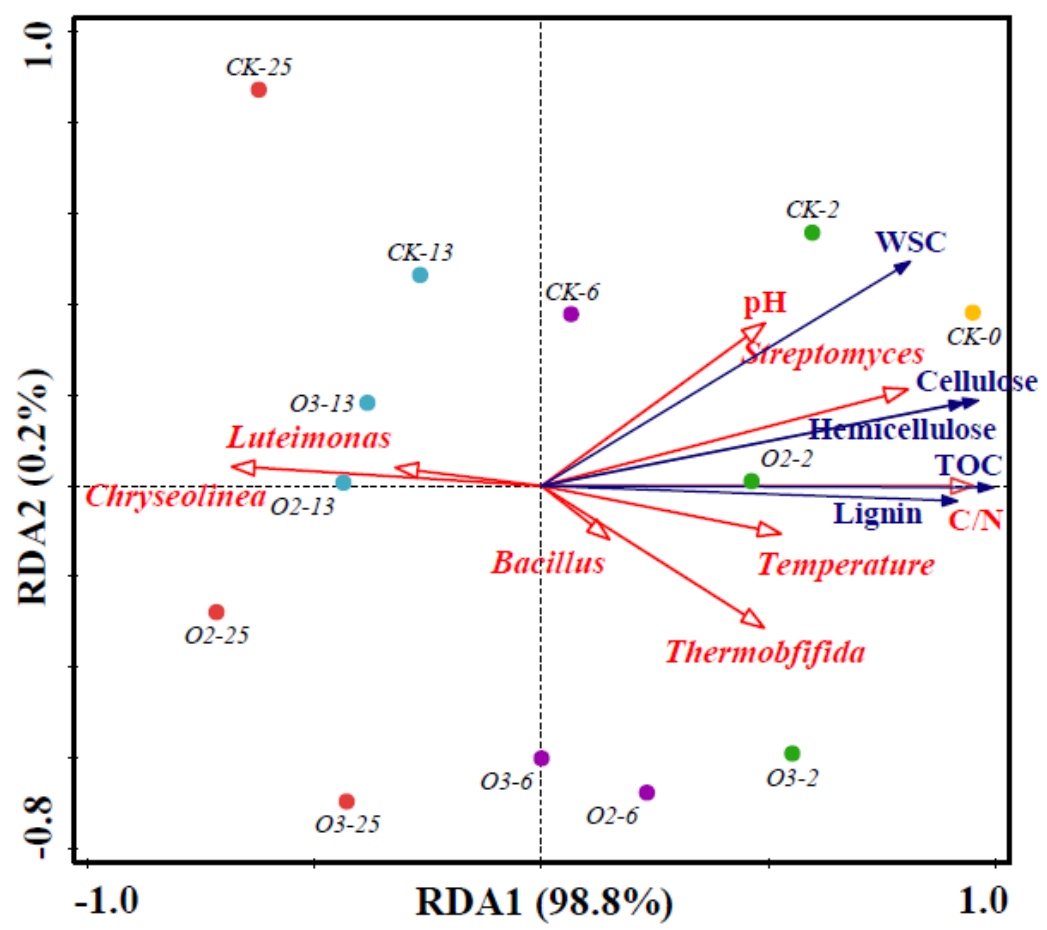

(a)

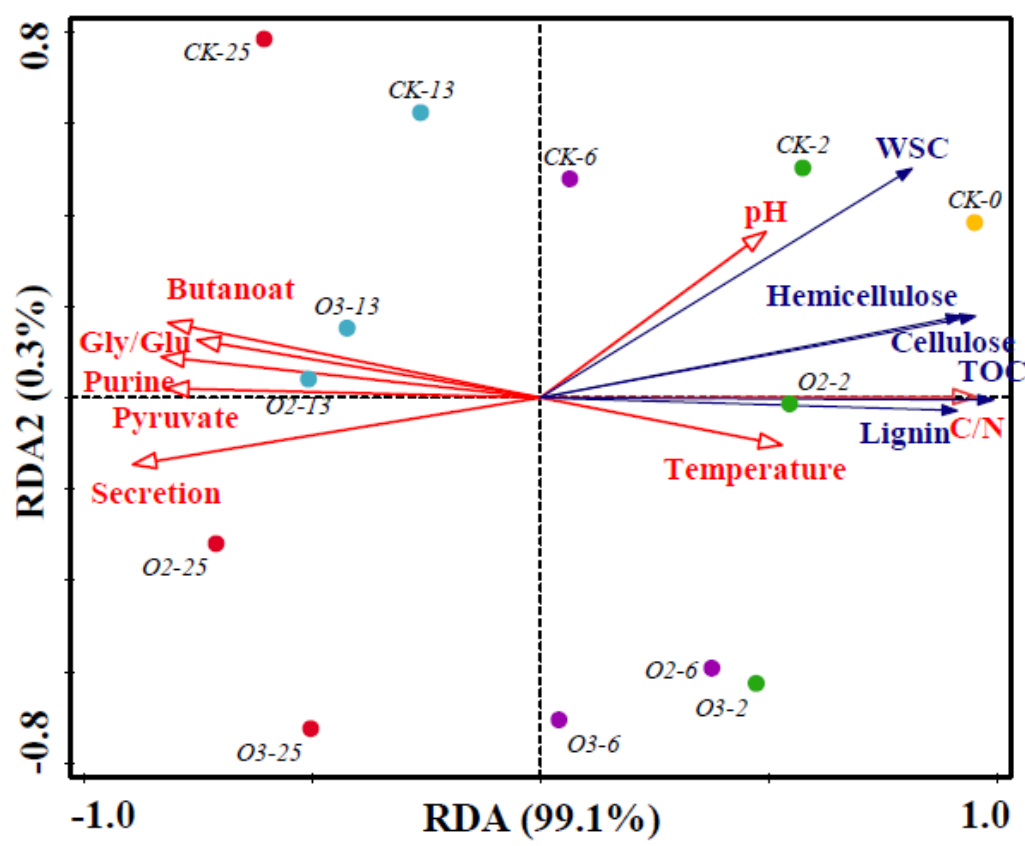

(b)

Figure 5

Redundancy analysis based on the compost properties, bacterial abundances, functional genes, and lignocellulose and carbon contents, where blue arrows represent lignocellulose and carbon, red arrows represent the compost properties, bacterial abundances, and functional genes, and dots represent the samples. 